\title{
SARS-CoV-2 Delta Variant Pathogenesis and Host Response in Syrian Hamsters
}

\author{
Sreelekshmy Mohandas ${ }^{1}\left(\mathbb{D}\right.$, Pragya Dhruv Yadav ${ }^{1, *}{ }^{-}$, Anita Shete $^{1}$, Dimpal Nyayanit ${ }^{1}$, Gajanan Sapkal ${ }^{1}$, \\ Kavita Lole ${ }^{1}$ and Nivedita Gupta ${ }^{2}$ \\ 1 Indian Council of Medical Research-National Institute of Virology, Pune 411021, India; \\ sreelekshmy88@gmail.com (S.M.); anitaaich2008@gmail.com (A.S.); dimpal.nyayanit@gmail.com (D.N.); \\ gajanansapkalniv@gmail.com (G.S.); lolekavita37@yahoo.com (K.L.) \\ 2 Indian Council of Medical Research, V. Ramalingaswami Bhawan, P.O. Box No. 4911, Ansari Nagar, \\ New Delhi 110029, India; drguptanivedita@gmail.com \\ * Correspondence: hellopragya22@gmail.com; Tel.: +91-20-2600-6111
}

check for updates

Citation: Mohandas, S.; Yadav, P.D.; Shete, A.; Nyayanit, D.; Sapkal, G.; Lole, K.; Gupta, N. SARS-CoV-2 Delta Variant Pathogenesis and Host Response in Syrian Hamsters. Viruses 2021, 13, 1773. https://doi.org/ 10.3390/v13091773

Academic Editor: Oliver Schildgen

Received: 23 July 2021

Accepted: 30 August 2021

Published: 5 September 2021

Publisher's Note: MDPI stays neutral with regard to jurisdictional claims in published maps and institutional affiliations.

Copyright: (C) 2021 by the authors Licensee MDPI, Basel, Switzerland. This article is an open access article distributed under the terms and conditions of the Creative Commons Attribution (CC BY) license (https:/ / creativecommons.org/licenses/by/ $4.0 /)$.

\begin{abstract}
B.1.617 is becoming a dominant Severe Acute Respiratory Syndrome-Coronavirus-2 (SARS-CoV-2) lineage worldwide with many sublineages, of which B.1.617.2 is designated as a variant of concern. The pathogenicity of B.1.617.2 (Delta) and B.1.617.3 lineage of SARS-CoV-2 was evaluated and compared with that of B.1, an early virus isolate with D614G mutation in a Syrian hamster model. Viral load, antibody response, and lung disease were studied. There was no significant difference in the virus shedding pattern among these variants. High levels of SARS-CoV-2 sub genomic RNA were detected in the respiratory tract of hamsters infected with the Delta variant for 14 days, which warrants further transmission studies. The Delta variant induced lung disease of moderate severity in about $40 \%$ of infected animals, which supports the attributed disease severity of the variant. Cross neutralizing antibodies were detected in animals infected with B.1, Delta, and B.1.617.3 variant, but neutralizing capacity was significantly lower with B.1.351 (Beta variant).
\end{abstract}

Keywords: SARS-CoV-2; Delta variant; B.1.617.2; B.1.617.3; Syrian hamster; pathogenicity

\section{Introduction}

Severe Acute Respiratory Syndrome-Coronavirus-2 (SARS-CoV-2) B.1.617 lineage variants were first reported in India in October 2020. Among the reported sublineages, B.1.617.1 is designated as a variant of interest and B.1.617.2 as a variant of concern (VOC) by the World Health Organization [1]. B.1.617.3 is another sublineage in which fewer sequences have been reported. The rise in COVID-19 cases worldwide during the second wave was speculated to be due to the high transmission potential of the Delta variant, which replaced the other variants in circulation [2]. As of 10 August 2021, the Delta variant has been reported in 142 countries [1]. The characteristic mutations reported in the spike gene of the B.1.617 lineage are D111D, L452R, D614G, P618R, and \pm E484Q [3]. These mutations suggest increased ACE2 binding, transmissibility, and escape of neutralization [3-6]. Available evidence suggests increased transmissibility, secondary attack rate, hospitalization risk, and immune escape by the Delta variant [1,7]. The potential impacts of the Delta variant on vaccine and therapeutic effectiveness are uncertain as limited data are available. Recent studies have reported neutralization efficiency in vaccinated individuals and resistance to monoclonal antibody therapy of the Delta variant [8-12].

Animal models have been used to explore various disease aspects of SARS-CoV-2 as well as for establishing the safety and efficacy of many interventional measures [13]. Studies have shown the high binding affinity of SARS-CoV-2 spike protein to hamster ACE2 receptor [14]. The virus replicates to high titre in the respiratory tract of Syrian hamsters and causes pneumonia [15]. The model has been utilized for studying SARS$\mathrm{CoV}-2$ pathology, immune response, and transmission, as well as many preclinical drug 
and vaccine trials [15-17]. With the emergence of new variants, it is important to generate information on disease characteristics and replicative fitness in the existing animal models. In the present study, pathogenicity and virus shedding differences of the Delta and B.1.617.3 variant in a Syrian hamster model were assessed. Cross-neutralization potential of sera of variant infected hamsters was also investigated. The study parameters were compared with that of B.1, an early SARS-CoV-2 variant.

\section{Materials and Methods}

\subsection{Virus and Cells}

SARS-CoV-2 variants Delta (GISAID identifier: EPI_ISL_2400521), B.1.617.3 (GISAID identifier: EPI_ISL_2497905), and B.1 (GISAID identifier: EPL_ISL_825084) were used for the animal study. For in vitro neutralization assay, B.1.351 (Beta variant) [GISAID identifier: EPI_ISL_2036294] was also used. The isolates were propagated and passaged twice in VeroCCL81 cells and sequence verified by next generation sequencing. The virus stock was titrated to determine the $50 \%$ tissue culture infective dose (TCID50) $/ \mathrm{mL}$.

\subsection{Animal Experiments}

To understand the virus shedding and pathogenicity, 54 female Syrian hamsters (8-10 weeks old) were divided into three groups of 18 animals each. The respective groups were challenged with $0.1 \mathrm{~mL}$ of $10^{5} \mathrm{TCID} 50 / \mathrm{mL}$ of B.1, Delta, and B.1.617.3 variants intranasally under isoflurane anesthesia. The animals were monitored for any clinical signs and body weight loss. Four hamsters were kept as mock control for the study. Throat swabs (TS), nasal wash (NW), and faecal samples were collected in $1 \mathrm{~mL}$ virus transport media (HiMedia, Mumbai, India) from six hamsters/group on 3, 5, 7, 10, 12, and 14 days post infection (DPI). To study the pathogenicity of each variant, four hamsters from each group were euthanized on 3,5,7, and 14 DPI by isoflurane anesthesia overdose to collect blood and organ samples.

\subsection{Viral RNA Detection}

Tissue samples were weighed and homogenized in $1 \mathrm{~mL}$ sterile media (GIBCO, Thermo Fisher Scientific, Waltham, MA, USA) and TS/NW/faeces samples were collected in $1 \mathrm{~mL}$ media. The same were used for RNA extraction using MagMAX ${ }^{\mathrm{TM}}$ Viral/Pathogen Nucleic Acid Isolation Kit as per the manufacturer's instructions. Real-time qRT-PCR was performed for E gene of SARS-CoV-2 to determine the viral genomic RNA (gRNA) load [18]. To measure the amount of replicating RNA, sub genomic (sg) N gene RNA was quantitated using published primers [19].

\subsection{Anti-SARS-CoV-2 Antibody Detection}

The serum samples collected on 3,5,7, and 14 DPI were tested for IgG antibodies by a hamster anti-SARS-CoV-2 IgG ELISA [20]. Plaque reduction neutralization test (PRNT) was performed to understand the neutralization ability of the sera of variant-infected hamsters with the Delta, B.1.617.3, B.1, and Beta variants in a biosafety level 3 facility [21]. Briefly, Vero CCL-81 $\left(1.0 \times 10^{5}\right.$ cells / mL $)$ was added per well in 24-well tissue culture plates. The cells were incubated for $24 \mathrm{~h}$ in a $\mathrm{CO}_{2}$ incubator to obtain a confluent monolayer. A fourfold serial dilution of heat-inactivated serum samples mixed with an equal volume of virus suspension containing 50-60 plaque forming units $/ 0.1 \mathrm{~mL}$ was incubated at $37^{\circ} \mathrm{C}$ for $1 \mathrm{~h}$. The virus-serum mixtures were added onto the cell monolayers and incubated with intermittent shaking. The mixtures were aspirated from the wells after $1 \mathrm{~h}$ and an overlay medium was added. The plates were further incubated at $37^{\circ} \mathrm{C}$ with $5 \% \mathrm{CO}_{2}$ for 4 days. The overlay medium was decanted and plates were stained with $1 \%$ amido black for $1 \mathrm{~h}$. Plaques were counted and PRNT50 was calculated using a log probit regression analysis by SPSS software (SPSS 15.0, SPSS Inc., Chicago, IL, USA). 


\subsection{Histopathological Examination}

The lung samples collected during necropsy were immersion fixed with $10 \%$ neutral buffered formalin. The tissues were processed with routine histopathological techniques and stained by hematoxylin and eosin. The lesions were graded on a numerical scale from 0 to 4 as no abnormality (0), minimal (1), mild (2), moderate (3), and severe (4) based on its severity by blinded scoring. Lesions graded include vascular inflammatory changes like congestion, hemorrhages, perivascular and peribronchial mononuclear cellular infiltration, bronchial pathological changes, alveolar changes like consolidation, hyaline changes, oedema, pneumocyte hyperplasia and septal thickening.

\subsection{Statistical Analysis}

The data collected from the study were analyzed using Graph pad Prism software (GraphPad Prism version 8.4.3, San Diego, CA, USA). For statistical analysis, non-parametric Mann Whitney test was used and $p$-values less than 0.05 were considered to be statistically significant.

\section{Results}

\subsection{Clinical Observations and Virus Shedding}

The average body weight gain in hamsters was the least in the Delta variant group compared with B.1 and B.1.617.3 during the first week of infection (Figure 1a). At 7 DPI, the mean percentage weight gain with standard deviation observed in the B.1, Delta, B.1.617.3, and mock control group was $6.72 \pm 4.1,0.3 \pm 7.2,2.15 \pm 4.3$, and $2.79 \pm 3.15$, respectively. For the Delta variant, the viral gRNA could be detected in the NW and TS samples until 7 DPI, whereas in a few animals of B.1 and B.1.617.3, it could be detected up to 12 and 14 DPI, respectively (Figure 1b-d). The viral load was higher in the TS and NW samples compared with faecal samples. The viral gRNA load was higher during the first week post infection, which decreased further in the B.1 and B.1.617.3 groups. After 5 DPI, sgRNA could be detected only in $1 / 6$ animals in the B.1 group and 2/6 animals in the B.1.617.3 group and in none of the animals in the Delta variant group (Figure 1e-g).

\subsection{Viral Load in the Respiratory Organs}

In the nasal turbinates, trachea, and lung samples, viral gRNA could be detected until day 14 (Figure 2a-c). Nasal turbinate showed a higher viral load compared with other organs in all of the groups. The SARS-CoV-2 viral RNA detected in the lungs, nasal turbinates, and trachea of hamsters infected with different variants did not show any statistical difference when compared among the groups on days 3,5 , and 7 post infection. By day 14, viral gRNA clearance was observed in 3/4 animals in the B.1 variantinfected group, whereas gRNA could be detected in all animals in the Delta and B.1.617.3 groups. The lung viral gRNA was significantly higher $(p=0.0286)$ in the samples of the B.1.617.3 variant on day 14 in comparison with B.1. The sgRNA could be detected in the lung and nasal turbinate samples until 7 DPI in all the groups. On 14 DPI, all the hamsters of the Delta variant-infected group showed significantly high sgRNA copies in nasal turbinates $\left(\right.$ mean $\left.=2.1 \times 10^{7} / \mathrm{mL}, p=0.0286\right)$ and lungs $\left(\right.$ mean $=2.1 \times 10^{6} / \mathrm{mL}$, $p=0.0286$ ), respectively, whereas in the B.1 and B.1.617.3 group, only $1 / 4$ hamsters showed the presence of sgRNA (Figure $2 \mathrm{~d}-\mathrm{f}$ ).

\subsection{Anti-SARS-CoV-2 Immune Response}

Anti-SARS-CoV-2 IgG antibodies were detected in all the groups from 3 DPI, showing an increasing optical density value in ELISA on further time points (Figure 3a). B.1 variant-infected hamsters showed about 1.7-fold geometric mean titre (GMT) reduction in neutralization titre against the Delta and B.1.617.3 variants, and 2.3-fold reduction against the Beta variant ( $p=0.0286)$, on 14 DPI. In the case of Delta and B.1.617.3 variant infection, a significant reduction $(p=0.0286)$ in GMT against the Beta variant i.e., about 2.5- and 2.9-fold reduction, was also seen on 14 DPI. The GMT in the case of Delta variantinfected hamster sera was 1.8-fold reduced against the B.1 and B.1.617.3 variants, whereas 
the titre of B.1.617.3 infected sera was found to be 1.1-fold reduced against the Delta variant and 1.3-fold reduced against the B.1 variant on 14 DPI.

\subsection{Lung Pathology in Infected Hamsters}

Grossly, 2/16 of B.1, 6/16 of B.1.617.2, and 3/ 16 of B.1.617.3 infected hamsters showed congestion and hemorrhages. A slightly higher mean lung weight to body weight ratio was observed on day 5 and 7 in the B.1.617.2 infected hamsters (Figure 4a). The cumulative lung histopathological score also showed Delta variant-infected animals with a higher average score during the first week of infection (Figure $4 \mathrm{~b}$ ). Three/twelve of the Delta and 1/12 of the B.1.617.3 infected hamsters sacrificed during the first week of infection showed diffuse areas of consolidation, hemorrhages, pneumocyte hyperplasia, septal thickening, and perivascular and peribronchial inflammatory cell infiltration of moderate severity, and one hamster in the B.1.617.2 group showed severe lesions (Figure 4c-f). Lung tissues showed minimal to mild pathological changes in the case of all the B.1 variant-infected hamsters. The lesions observed were mostly focal on all days of sacrifice, except in 2/4 hamsters sacrificed on both day 5 and 7, which showed multifocal areas of consolidation and mononuclear cell infiltration (Figure $4 \mathrm{~g}, \mathrm{~h}$ ).

(a)
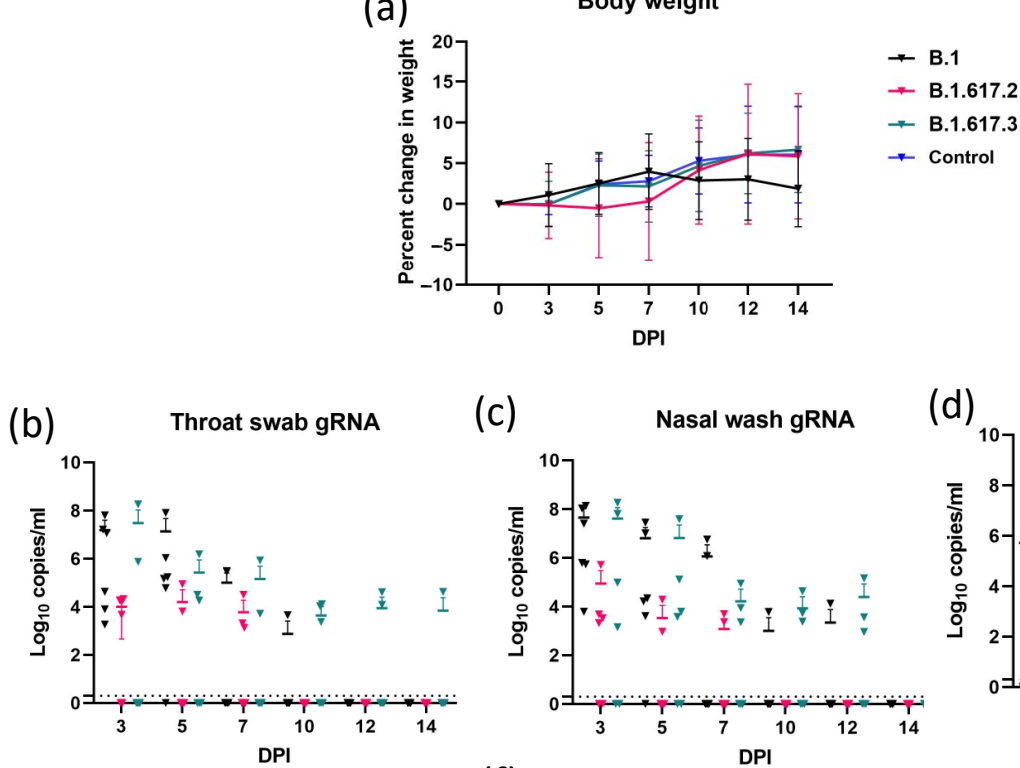

(c)
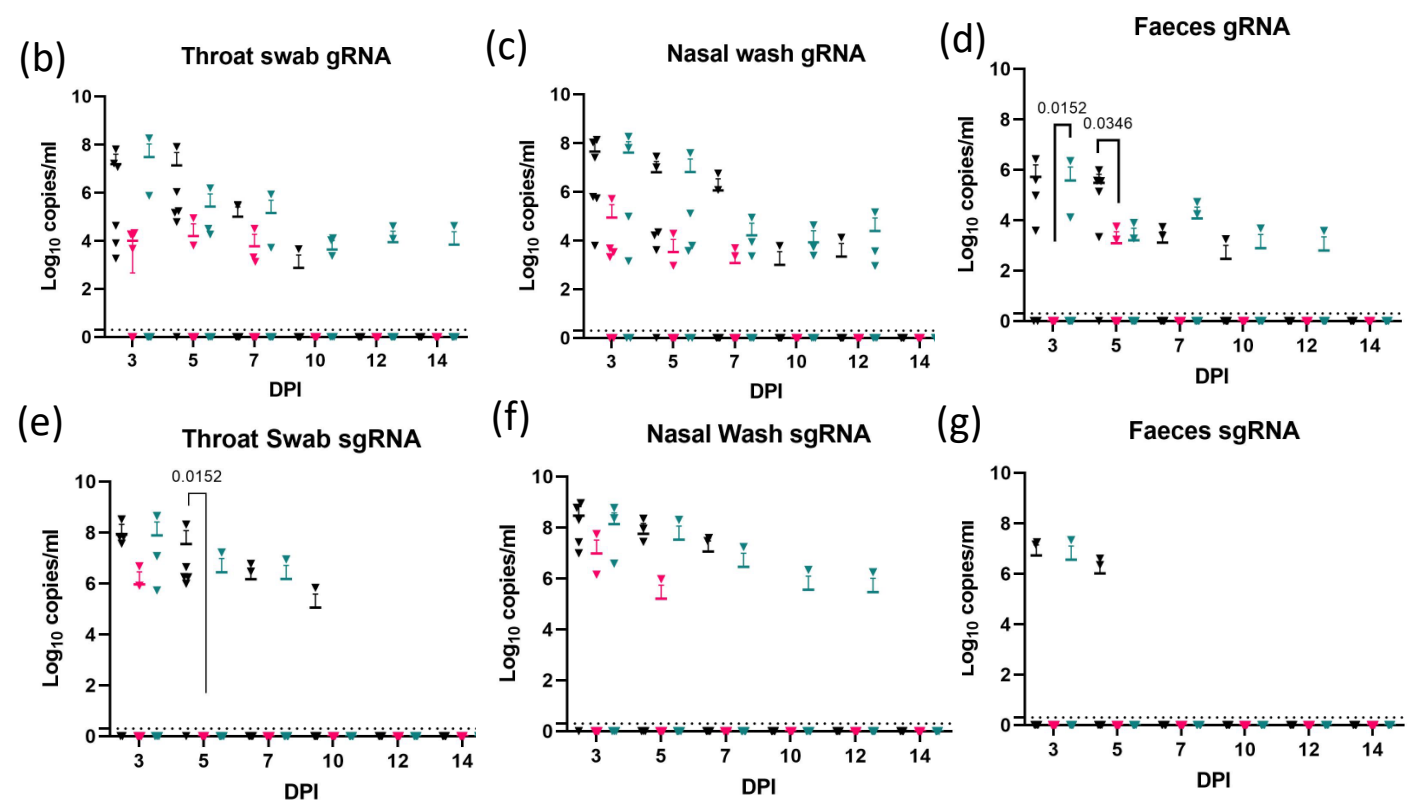

Figure 1. Bodyweight and virus shed by hamsters post challenge with SARS-CoV-2 variants. (a) Percent body weight changes in hamsters post virus infection at days $3(n=18) ; 5(n=14) ; 7(n=10)$; and 10,12, and $14(n=6)$, as well as in mock control hamsters $(n=4)$. Viral genomic RNA load $\left(\log _{10}\right.$ viral genomic RNA copy numbers $\left./ \mathrm{mL}\right)$ in $(\mathbf{b})$ throat swab, (c) nasal wash, and (d) faeces samples collected on 3, 5, 7, 10, 12, and 14 days post infection (DPI). Viral sub genomic mRNA load $\left(\log _{10}\right.$ viral subgenomic RNA copy numbers $/ \mathrm{mL}$ ) in (e) throat swab, (f) nasal wash, and (g) faeces in hamsters post virus challenge on $3,5,7,10,12$, and 14 DPI. The mean along with standard deviation is depicted in the scatter plot. The statistical significance was assessed using the non-parametric Mann-Whitney tests and $p$-values less than 0.05 were considered to be statistically significant. The dotted line indicates the limit of detection of the assay. 
(a)

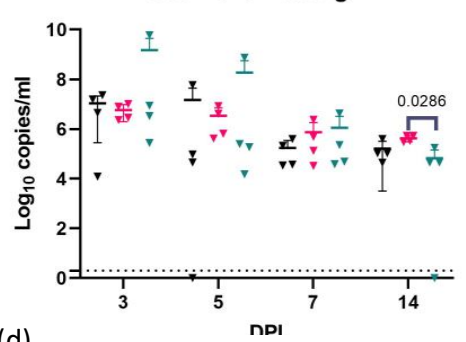

(d)

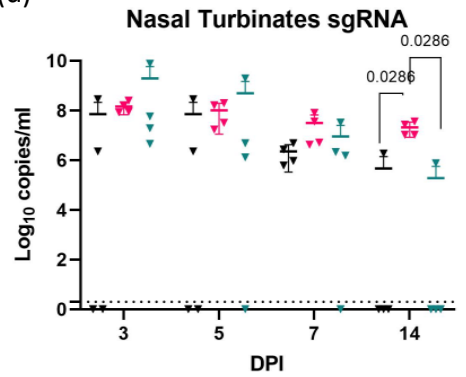

(b)

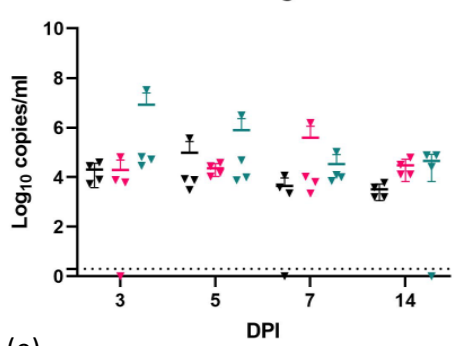

(e)

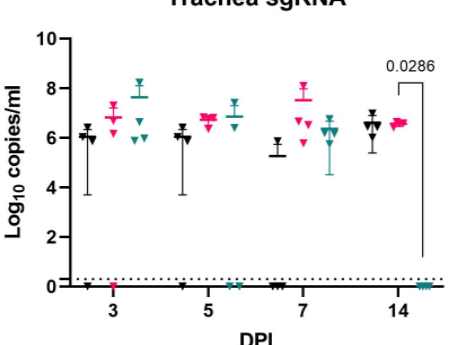

(c) Lungs gRNA

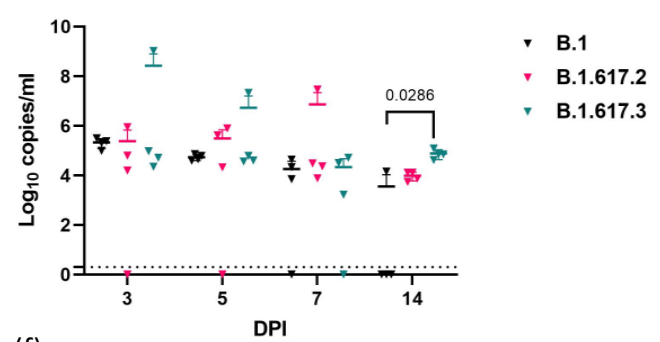

(f)

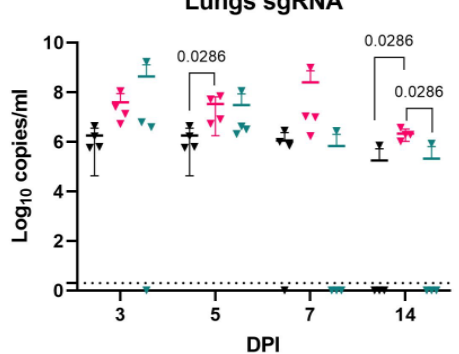

Figure 2. Viral load in respiratory tract samples of hamsters post infection. Viral genomic RNA load (log 10 viral genomic RNA copies $/ \mathrm{mL}$ ) in (a) nasal turbinates, (b) trachea, and (c) lung samples collected on 3, 5, 7, and 14 DPI, represented as mean with standard deviation in a scatter plot. Viral sub genomic RNA load ( $\log _{10}$ viral subgenomic RNA copies/mL) in (d) nasal turbinates, (e) trachea, and (f) lung samples collected on 3, 5, 7, and 14 DPI, represented as mean with standard deviation in a scatter plot. The statistical significance was assessed using the non-parametric Mann-Whitney tests, and $p$-values less than 0.05 were considered to be statistically significant. The dotted line indicates the limit of detection of the assay.

(a)

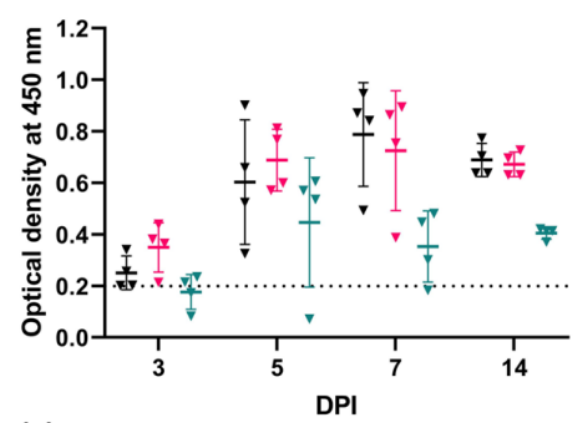

(c)

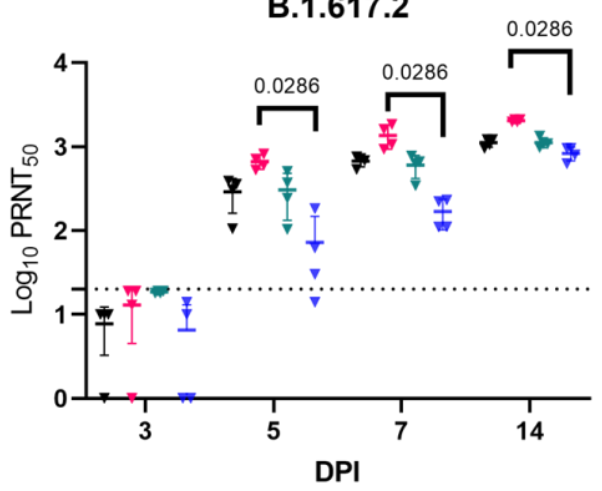

(b)

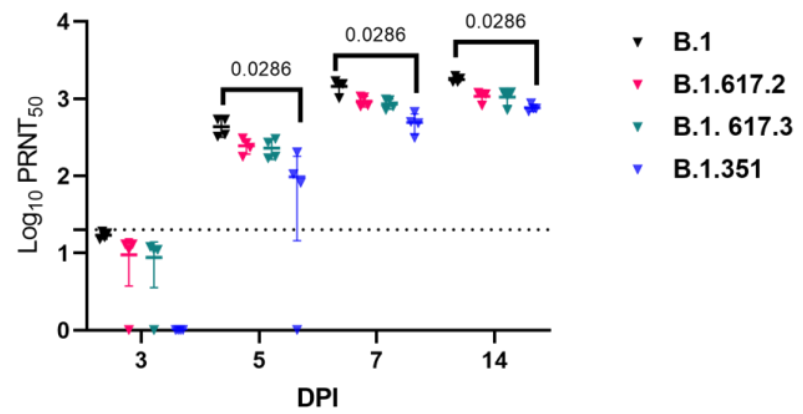

(d)

B.1.617.3

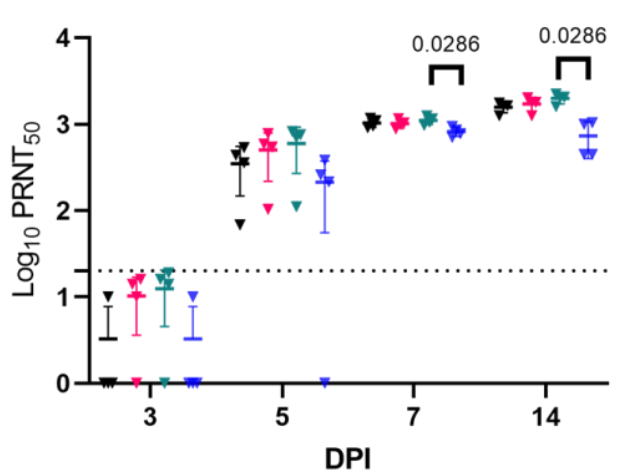

Figure 3. Antibody response in hamsters post challenge with SARS-CoV-2 variants. (a) Anti-SARS-CoV-2 IgG response in hamsters post virus infection by ELISA. Neutralizing antibody response in hamsters infected with the (b) B.1, (c) B.1.617.2 (Delta), and (d) B.1.617.3 variants against B.1, Delta, B.1.617.3, and B.1.351 (Beta). The dotted line indicates the limit of detection of the assay. The mean along with standard deviation is depicted in the scatter plot. The statistical significance was assessed using the non-parametric Mann-Whitney tests, and $p$-values less than 0.05 were considered to be statistically significant. 
(a)
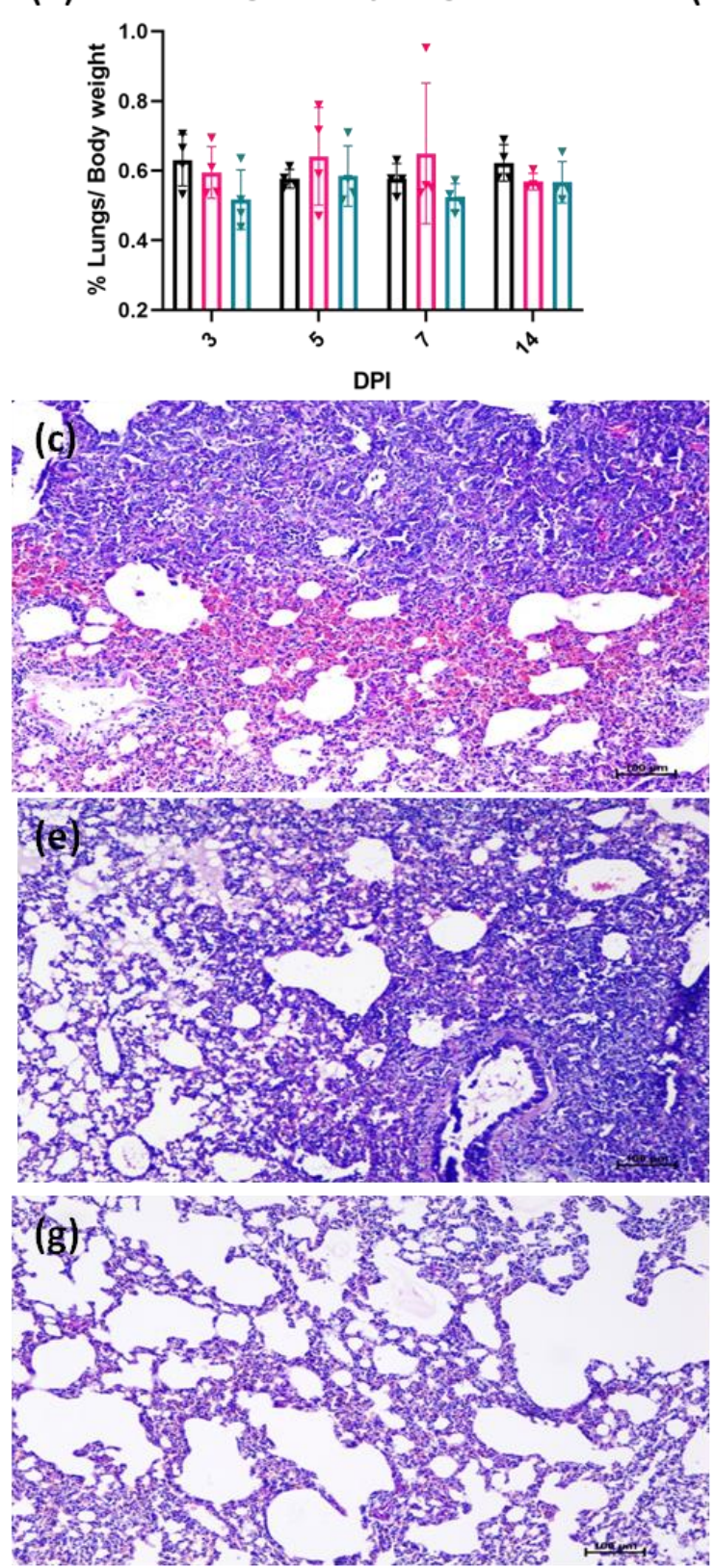

(b)

Histopathology Score
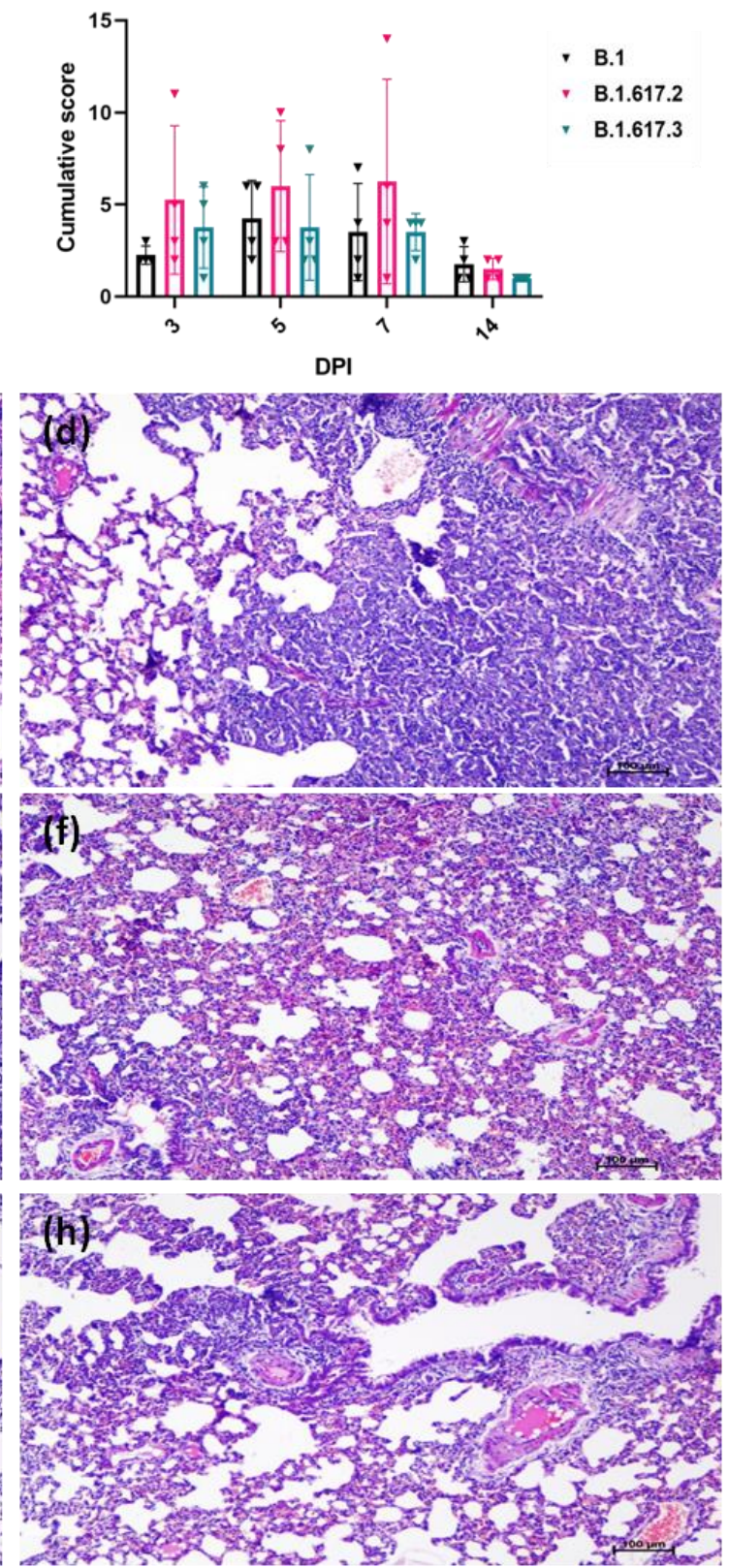

Figure 4. Pathological changes in lungs observed at necropsy in hamsters post infection with the B.1, Delta, and B.1.617.3 variants. (a) Proportion of lung weight to body weight of hamsters at necropsy represented as mean with standard deviation. (b) Cumulative lung histopathology score in hamsters infected with SARS-CoV-2 variants represented as mean with standard deviation. Lungs of Delta variant-infected hamsters showing (c) diffuse alveolar damage with congestion and hemorrhages in the lung parenchyma, as well as (d) diffuse mononuclear infiltration, pneumocyte hyperplasia and septal thickening with mild congestion. Lungs of B.1.617.3 infected hamsters showing (e) alveolar septal thickening, exudation and hyaline changes in the alveoli, as well as (f) congestion and alveolar septal thickening. Lungs of B.1 infected hamster showing (g) few small foci of mononuclear cell infiltration and (h) congestion and perivascular inflammatory cell infiltration.

\section{Discussion}

The Delta variant possesses SARS-CoV-2 spike protein mutations that are known to affect virus transmissibility and neutralization. The secondary attack rate of the variant is also higher compared with the Alpha variant [7]. The variant is spreading faster across the 
globe to become a dominant variant in many countries [1]. We observed viral replication in the respiratory tract of hamsters post infection with the B.1.617 variant with minimal or no weight loss. Higher viral load in the throat and nasal swab samples was observed in the first week compared with faecal samples, indicating respiratory tract tropism. Earlier studies on various SARS-CoV-2 isolates of different lineages have also reported high viral loads in the initial week of infection in humans [22]. Viral sgRNA is considered to be an indicator of active infection [22]. We observed gRNA and sgRNA in the respiratory organs until 14 days. However, prolonged shedding of the virus could not be observed with any of the variants studied here, as reported in human cases [23]. The sensitivity of detection of viral sgRNA by nasal wash sampling post 1 week when viral gRNA load declines is less as per our observations in earlier studies in Syrian hamsters [16,24-26]. The prolonged detection of sgRNA in the nasal turbinates and lungs of B.1.617.2 could be a contributing factor to support the increased transmissibility attributed to this variant. Transmission experiments should be further performed to understand the significance of this finding. In human COVID-19 cases, where the presence of sgRNA is studied, it is found that it is rarely detectable post 8 days of illness [27,28]. A study from England has shown increased household transmission associated with the Delta variant compared with the Alpha variant, which was previously reported to be highly transmissible [29]. Increased transmissibility and immune escape have led to the sudden rise in COVID-19 cases due to the Delta variant [30].

Lung disease with severe lesions could be observed in the case of 4/8 Delta variantinfected hamsters sacrificed on day 5 and 7 , indicating the potential of the variant to cause severe disease. The histopathological lesions observed were similar to the earlier reports in hamsters with an onset of inflammatory changes by $3 \mathrm{DPI}$, which progress to interstitial pneumonia and a complete recovery by 14 DPI [31]. Even though high levels of sgRNA and pneumonic changes could be detected in the lungs of B.1.617.2 infected hamsters compared with other variants, we could not observe any significant body weight loss post infection in hamsters as reported earlier, probably owing to the dose of inoculum. The minimal lesions observed with other variants could be also because of the same reason, as we have observed severe lesions and body weight loss in hamsters infected with a dose of $10^{6.5} \mathrm{TCID} 50 / \mathrm{mL}$ of the B.1 variant in our earlier studies [24]. The Delta variant has shown increased replication and enhanced entry efficiency in in vitro experiments [28]. An increased fitness advantage of the variant has been observed in the respiratory organoid system compared with wild type SARS-CoV-2 [28]. Reports from England and Scotland have shown an increased risk of hospitalization in the case of the B.1.617.2 variant cases [7]. Our earlier studies on pathogenicity of B.1.617.1, a variant of the same lineage in the hamster model, have shown severe lung disease [24].

The initiation of IgG response was observed as early as on 3 DPI. This finding was in contrast to our earlier studies in hamsters, where no IgG response could be observed on 3 DPI. This could probably be because of the difference in the virus inoculum dose and age of hamsters used [16,32]. The sample size of the study was also limited [16,32]. Day 3 sera were found to be non-neutralizing by the live virus neutralization assay. In neutralization studies, a significant reduction was observed in case of the Beta variant among all the variants studied. The Beta variant is known for reduced neutralization by many monoclonal antibodies and convalescent sera from patients infected with early SARS-CoV-2 isolates [30,33]. Although not significant, a reduction was also seen in the case of B.1 infected hamster sera with the Delta variant. Mlcochova et al., 2021 reported 20 to $55 \%$ immune evasion by the Delta variant in the case of prior infections with nonB.1.617.2 lineages [34]. B.1.617.3 possesses the E484Q mutation, which is a known site in RBD, which can impact the serum neutralization efficiency [6]. Even though we observed a reduced IgG antibody response in the case of B.1.617.3 compared with the other two variants at $14 \mathrm{DPI}$, we found the B.1.617.3 infected animal sera showing comparable neutralizing titres with the B.1 and Delta variants. Few recent studies reported reduced neutralization of the Delta variant by the BNT162b2 mRNA vaccine [8,9]. Another study 
reported only modest differences in the protective antibody titres against the Delta variant following two doses of the BNT162b2 or ChAdOx1 vaccine [10]. B.1.617 was found to be resistant to certain monoclonal antibodies approved for COVID-19 treatment such as Bamlanivimab and REGN10933 [11,12]. In India, sera neutralization studies on Covishield and Covaxin vaccine recipients showed neutralization potential against B.1.617.1 and B.1.617.2, respectively [32,35].

In the present study, we observed no significant difference in viral RNA shedding among the different variants studied. Higher sgRNA levels could be detected in the respiratory tract of Delta variant-infected hamsters for a prolonged period, which should be investigated further for its transmission potential. The Delta variant induced the least body weight gain and lung disease of severity in about $40 \%$ of infected animals, indicating its pathogenic potential. Cross neutralizing antibodies were observed in variant-infected hamsters. The neutralizing response was considerably lower with the B.1.351 variant. The evidence from the present study shows that Delta variant infection generates a broader neutralizing response and is not as immune-evasive as B.1.351.

Author Contributions: Conceptualization, P.D.Y. and S.M.; methodology, P.D.Y., S.M., A.S. and G.S.; software, D.N.; validation, P.D.Y. and A.S.; formal analysis, D.N. and S.M.; investigation, P.D.Y. and S.M.; resources, P.D.Y., G.S. and K.L.; data curation, P.D.Y.; writing-original draft preparation, S.M.; writing-review and editing, P.D.Y. and N.G.; visualization, P.D.Y.; supervision, P.D.Y.; project administration, P.D.Y.; funding acquisition, P.D.Y. and N.G. All authors have read and agreed to the published version of the manuscript.

Funding: This research was funded by Indian Council of Medical Research as intramural funding for COVID-19 research to ICMR-National Institute of Virology, Pune.

Institutional Review Board Statement: The study was approved by the Institutional Animal Ethics Committee, ICMR-National Institute of Virology, Pune (Approval no.: NIV/IAEC/2021/MCL/01), and all the experiments were performed as per the guidelines of the Committee for the Purpose of Control and Supervision of Experiments in Animals, Government of India.

Informed Consent Statement: Not applicable.

Data Availability Statement: All the data pertaining to the study are available in the manuscript.

Acknowledgments: The authors gratefully acknowledge the encouragement and support extended by Balram Bhargava, Secretary to the Government of India, Department of Health Research, Ministry of Health \& Family Welfare \& Director-General, ICMR; Samiran Panda, Head of Epidemiology and Communicable Diseases, ICMR; and Priya Abraham, Director, ICMR-National Institute of Virology, Pune. The authors are thankful to Manoj Kadam, Abhimanyu Kumar, Annasaheb Suryawanshi, Gururaj Deshpande, Rajen Lakra, Rajlaxmi Jain, Prasad Sarkale, Shreekant Baradkar, Chetan Patil, Asha Salunke, Supriya Hundekar, Pranita Gawande, Ashwini Waghmare, Kaumudi Kalele, Kundan Wakchaure, Shilpa Ray, Poonam Bodake, and Priyanka Waghmare of ICMR-NIV, Pune. We also thank Chandrasekhar Mote, Krantisinh Nana Patil College of Veterinary Science, Shirwal, Maharashtra.

Conflicts of Interest: The authors declare no conflict of interest.

\section{References}

1. Weekly Epidemiological Update on COVID-19-10 August 2021. Available online: https://www.who.int/publications/m/item/ weekly-epidemiological-update-on-COVID-19---10-august-2021 (accessed on 16 August 2021).

2. Ranjan, R.; Sharma, A.; Verma, M.K. Characterization of the Second Wave of COVID-19 in India. medRxiv 2021. [CrossRef]

3. Cherian, S.; Potdar, V.; Jadhav, S.; Yadav, P.; Gupta, N.; Das, M.; Rakshit, P.; Singh, S.; Abraham, P.; Panda, S. SARS-CoV-2 Spike Mutations, L452R, T478K, E484Q and P681R, in the Second Wave of COVID-19 in Maharashtra, India. Microrganisms 2021, 9 , 1542. [CrossRef]

4. Volz, E.; Hill, V.; McCrone, J.T.; Price, A.; Jorgensen, D.; O’Toole, Á.; Southgate, J.; Johnson, R.; Jackson, B.; Nascimento, F.F. Evaluating the Effects of SARS-CoV-2 Spike Mutation D614G on Transmissibility and Pathogenicity. Cell 2021, 184, 64-75.e11. [CrossRef]

5. Motozono, C.; Toyoda, M.; Zahradnik, J.; Ikeda, T.; Saito, A.; Tan, T.S.; Ngare, I.; Nasser, H.; Kimura, I.; Uriu, K.; et al. SARS-CoV-2 spike L452R variant evades cellular immunity and increases infectivity. Cell Host Microbe 2021, 29, 1124-1136. [CrossRef] 
6. Greaney, A.J.; Loes, A.N.; Crawford, K.H.; Starr, T.N.; Malone, K.D.; Chu, H.Y.; Bloom, J.D. Comprehensive Mapping of Mutations in the SARS-CoV-2 Receptor-Binding Domain That Affect Recognition by Polyclonal Human Plasma Antibodies. Cell Host Microbe 2021, 29, 463-476.e6. [CrossRef]

7. Risk Assessment for SARS-CoV-2 Variant: VOC-21APR-02 (B.1.617.2). 2021. Available online: https://assets.publishing.service. gov.uk/government/uploads/system/uploads/attachment_data/file/991135/3_June_2021_Risk_assessment_for_SARS-CoV2_variant_DELTA.pdf (accessed on 20 July 2021).

8. Edara, V.-V.; Lai, L.; Sahoo, M.; Floyd, K.; Sibai, M.; Solis, D.; Flowers, M.W.; Hussaini, L.; Ciric, C.R.; Bechnack, S.; et al. Infection and Vaccine-Induced Neutralizing Antibody Responses to the SARS-CoV-2 B. 1.617 Variants. N. Engl. J. Med. 2021, 385, 664-666. [CrossRef]

9. Wall, E.C.; Wu, M.; Harvey, R.; Kelly, G.; Warchal, S.; Sawyer, C.; Daniels, R.; Hobson, P.; Hatipoglu, E.; Ngai, Y. Neutralising Antibody Activity against SARS-CoV-2 VOCs B. 1.617. 2 and B. 1.351 by BNT162b2 Vaccination. Lancet 2021, 397, 2331-2333. [CrossRef]

10. Bernal, J.L.; Andrews, N.; Gower, C.; Gallagher, E.; Simmons, R.; Thelwall, S.; Tessier, E.; Groves, N.; Dabrera, G.; Myers, R. Effectiveness of COVID-19 Vaccines against the B. 1.617. 2 Variant. N. Engl. J. Med. 2021, 385, 585-594. [CrossRef]

11. Planas, D.; Veyer, D.; Baidaliuk, A.; Staropoli, I.; Guivel-Benhassine, F.; Rajah, M.; Planchais, C.; Porrot, F.; Robillard, N.; Puech, J. Reduced Sensitivity of Infectious SARS-CoV-2 Variant B. 1.617. 2 to Monoclonal Antibodies and Sera from Convalescent and Vaccinated Individuals. Nature 2021, 596, 276-280. [CrossRef]

12. Hoffmann, M.; Hofmann-Winkler, H.; Krüger, N.; Kempf, A.; Nehlmeier, I.; Graichen, L.; Arora, P.; Sidarovich, A.; Moldenhauer, A.-S.; Winkler, M.S. SARS-CoV-2 Variant B. 1.617 Is Resistant to Bamlanivimab and Evades Antibodies Induced by Infection and Vaccination. Cell Rep. 2021, 36, 109415. [CrossRef]

13. Muñoz-Fontela, C.; Dowling, W.E.; Funnell, S.G.; Gsell, P.S.; Riveros-Balta, A.X.; Albrecht, R.A.; Andersen, H.; Baric, R.S.; Carroll, M.W.; Cavaleri, M.; et al. Animal models for COVID-19. Nature 2020, 586, 509-515. [CrossRef]

14. Piplani, S.; Singh, P.K.; Winkler, D.A.; Petrovsky, N. In silico comparison of SARS-CoV-2 spike protein-ACE2 binding affinities across species and implications for virus origin. Sci. Rep. 2021, 11, 1-3. [CrossRef]

15. Sia, S.F.; Yan, L.M.; Chin, A.W.; Fung, K.; Choy, K.T.; Wong, A.Y.; Kaewpreedee, P.; Perera, R.A.; Poon, L.L.; Nicholls, J.M.; et al. Pathogenesis and transmission of SARS-CoV-2 in golden hamsters. Nature 2020, 583, 834-838. [CrossRef]

16. Mohandas, S.; Yadav, P.D.; Shete-Aich, A.; Abraham, P.; Vadrevu, K.M.; Sapkal, G.; Mote, C.; Nyayanit, D.; Gupta, N.; Srinivas, V.K. Immunogenicity and Protective Efficacy of BBV152, Whole Virion Inactivated SARS-CoV-2 Vaccine Candidates in the Syrian Hamster Model. IScience 2021, 24, 102054. [CrossRef]

17. Ye, Z.W.; Yuan, S.; Chan, J.F.; Zhang, A.J.; Yu, C.Y.; Ong, C.P.; Yang, D.; Chan, C.C.; Tang, K.; Cao, J.; et al. Beneficial effect of combinational methylprednisolone and remdesivir in hamster model of SARS-CoV-2 infection. Emerg. Microbes Infect. 2021, 10, 291-304. [CrossRef]

18. Choudhary, M.L.; Vipat, V.; Jadhav, S.; Basu, A.; Cherian, S.; Abraham, P.; Potdar, V.A. Development of in Vitro Transcribed RNA as Positive Control for Laboratory Diagnosis of SARS-CoV-2 in India. Indian J. Med. Res. 2020, 151, 251.

19. Moreira, L.V.L.; de Souza Luna, L.K.; Barbosa, G.R.; Perosa, A.H.; Chaves, A.P.C.; Conte, D.D.; Carvalho, J.M.A.; Bellei, N. Test on Stool Samples Improves the Diagnosis of Hospitalized Patients: Detection of SARS-CoV-2 Genomic and Subgenomic RNA. J. Infect. 2021, 82, 186-230. [CrossRef]

20. Shete, A.; Mohandas, S.; Jain, R.; Yadav, P.D. A Qualitative IgG ELISA for Detection of SARS-CoV-2-Specific Antibodies in Syrian Hamster Serum Samples. STAR Protoc. 2021, 2, 100573. [CrossRef]

21. Deshpande, G.R.; Sapkal, G.N.; Tilekar, B.N.; Yadav, P.D.; Gurav, Y.; Gaikwad, S.; Kaushal, H.; Deshpande, K.S.; Kaduskar, O.; Sarkale, P. Neutralizing Antibody Responses to SARS-CoV-2 in COVID-19 Patients. Indian J. Med. Res. 2020, $152,82$.

22. Wölfel, R.; Corman, V.M.; Guggemos, W.; Seilmaier, M.; Zange, S.; Müller, M.A.; Niemeyer, D.; Jones, T.C.; Vollmar, P.; Rothe, C. Virological Assessment of Hospitalized Patients with COVID-2019. Nature 2020, 581, 465-469. [CrossRef]

23. Yuan, C.; Wang, H.; Li, K.; Tang, A.; Dai, Y.; Wu, B.; Zhang, H.; Chen, J.; Liu, J.; Wu, W.; et al. SARS-CoV-2 Viral Shedding Characteristics and Potential Evidence for the Priority for Faecal Specimen Testing in Diagnosis. PLoS ONE 2021, 16, e0247367. [CrossRef]

24. Yadav, P.D.; Mohandas, S.; Shete, A.M.; Nyayanit, D.A.; Gupta, N.; Patil, D.Y.; Sapkal, G.N.; Potdar, V.; Kadam, M.; Kumar, S.; et al. SARS CoV-2 variant B. 1.617. 1 is highly pathogenic in hamsters than B. 1 variant. bioRxiv 2021. [CrossRef]

25. Yadav, P.; Mohandas, S.; Sarkale, P.; Nyayanit, D.; Shete, A.; Sahay, R.; Potdar, V.; Baradkar, S.; Gupta, N.; Sapkal, G.; et al. Isolation of SARS-CoV-2 B. 1.1. 28.2 P2 variant and pathogenicity comparison with D614G variant in hamster model. bioRxiv 2021. [CrossRef]

26. Mohandas, S.; Yadav, P.D.; Nyayanit, D.; Deshpande, G.; Aich, A.S.; Sapkal, G.; Kumar, S.; Jain, R.; Kadam, M.; Kumar, A.; et al. Comparison of the pathogenicity and virus shedding of SARS CoV-2 VOC 202012/01 and D614G variant in hamster model. bioRxiv 2021. [CrossRef]

27. Perera, R.A.; Tso, E.; Tsang, O.T.; Tsang, D.N.; Fung, K.; Leung, Y.W.; Chin, A.W.; Chu, D.K.; Cheng, S.M.; Poon, L.L. SARS-CoV-2 Virus Culture and Subgenomic RNA for Respiratory Specimens from Patients with Mild Coronavirus Disease. Emerg. Infect. Dis. 2020, 26, 2701. [CrossRef]

28. Anand, K.B.; Karade, S.; Sen, S.; Ray, S.; Patil, P.; Thosani, P.; Shergill, S.P.; Gupta, R.M. Can Subgenomic MRNA Predict Course of COVID-19?-An Observational Study from a Tertiary Care Center. J. Mar. Med. Soc. 2020, 22, 216. [CrossRef] 
29. Allen, H.; Vusirikala, A.; Flannagan, J.; Twohig, K.A.; Zaidi, A.; COG-UK Consortium; Groves, N.; Lopez-Bernal, J.; Harris, R.; Charlett, A.; et al. Increased Household Transmission of COVID-19 Cases Associated with SARS-CoV-2 Variant of Concern B.1.617.2: A National Case Control Study. Available online: https://khub.net/documents/135939561/405676950/Increased+ Household+Transmission+of+COVID-19+Cases+-+national+case+study.pdf/7f7764fb-ecb0-da31-77b3-b1a8ef7be9aa (accessed on 20 July 2021).

30. Mlcochova, P.; Kemp, S.; Dhar, M.S.; Papa, G.; Meng, B.; Mishra, S.; Whittaker, C.; Mellan, T.; Ferreira, I.; Datir, R. SARS-CoV-2 B. 1.617. 2 Delta Variant Emergence and Vaccine Breakthrough. bioRxiv 2021. [CrossRef]

31. Gruber, A.D.; Osterrieder, N.; Bertzbach, L.D.; Vladimirova, D.; Greuel, S.; Thlow, J.; Horst, D.; Trimpert, J.; Dietert, K. Standardization of Reporting Criteria for Lung Pathology in SARS-CoV-2-infected Hamsters: What Matters? Am. J. Respir. Cell Mol. Biol. 2020, 63, 856-859. [CrossRef]

32. Mohandas, S.; Jain, R.; Yadav, P.D.; Shete-Aich, A.; Sarkale, P.; Kadam, M.; Kumar, A.; Deshpande, G.; Baradkar, S.; Patil, S.; et al. Evaluation of the susceptibility of mice and hamsters to SARS-CoV-2 infection. Indian J. Med. Res. 2020, 151, 479.

33. Zhou, D.; Dejnirattisai, W.; Supasa, P.; Liu, C.; Mentzer, A.J.; Ginn, H.M.; Zhao, Y.; Duyvesteyn, H.M.; Tuekprakhon, A.; Nutalai, R. Evidence of Escape of SARS-CoV-2 Variant B. 1.351 from Natural and Vaccine-Induced Sera. Cell 2021, 184, 2348-2361.e6. [CrossRef]

34. Yadav, P.; Sapkal, G.N.; Abraham, P.; Deshpande, G.; Nyayanit, D.; Patil, D.Y.; Gupta, N.; Sahay, R.R.; Shete, A.; Kumar, S.; et al. Neutralization potential of Covishield vaccinated individuals sera against B. 1.617. 1. Clin. Infect. Dis. 2021, ciab483. [CrossRef] [PubMed]

35. Yadav, P.D.; Sapkal, G.; Ella, R.; Sahay, R.R.; Nyayanit, D.A.; Patil, D.Y.; Deshpande, G.; Shete, A.M.; Gupta, N.; Mohan, V.K.; et al. Neutralization of Beta and Delta variant with sera of COVID-19 recovered cases and vaccinees of inactivated COVID-19 vaccine BBV152/Covaxin. J. Travel Med. 2021, taab104. [CrossRef] [PubMed] 